\title{
Advanced gas leakage, fire and power supply failure monitoring system
}

\author{
Amirul Asraf Roslan, Rahimi Baharom \\ Faculty of Electrical Engineering, Universiti Teknologi MARA, Malaysia
}

\begin{abstract}
Article Info
Article history:

Received Mar 1, 2019

Revised Jun 3, 2019

Accepted Jun 27, 2019

\section{Keywords:}

Arduino UNO

GSM module

Short message service

Smart safety monitoring system

ABSTRACT

Safety system such as smoke detector and fire alarm are considered to be a counter measure for fire accident. This safety system is important as it acts as a security measure against fire accident which could lead to death and destruction of properties. This paper propose an advanced gas leakage, fire and power supply failure monitoring system with Arduino UNO and GSM Module as its embedded system. Among the features of this system are their ability to detect the presence of smoke, gases and power failure at homes and factories, then the system will send a text message using Short Message Service (SMS) to the registered mobile number via GSM Module informing the user the situation and location of the incident. As a result, the user or person in charge can respond to the emergency situation accordingly and alert the fire departments or relevant authorities in time. This system could help the user to transform the way they protect their property and critical infrastructure. Successful safety and security transformation requires a combination of end user structural and operational changes as well as technology evolution enablement. This is in line with the Fourth Industrial Revolution (known as IR4.0), that propose substantial increase in the deployment of sensors for collecting, processing, and communicating measurement data in real time in order to diverse working environments, thus, resulting in advancement and convergence of technologies.
\end{abstract}

Copyright ( 2020 Institute of Advanced Engineering and Science. All rights reserved.

\section{Corresponding Author:}

Rahimi Baharom,

Faculty of Electrical Engineering, Universiti Teknologi MARA, 40450 Shah Alam, Selangor, Malaysia.

Email: rahimi6579@gmail.com

\section{INTRODUCTION}

Nowadays, lack of communication and system interoperability is one of the biggest issues facing Public Safety Answering Points, Emergency Operations Centre's, Rescue Services and other first line responders. Lack of smart fire detection system and physical visualization contribute to delay in contacting the fire department [1]. Detecting fire outbreak earlier can provide more time to prevent it from spreading and causes massive damage and losses [2]. In the event of gas leakage which is not instantly detected and no measures are taken, it might induce detonation and serious harm to lives and community [3]. Installation of a safety system in houses or buildings such as fire alarms or smoke detectors is important as it can not only save lives and minimize injuries, but also can prevent or decrease the losses due to properties or assets destroyed in a fire. Controlled fire can be of use, but fire that goes out of control can cause death and destruction of property [4]. In the United States, it was reported that between the years 2007 to 2011, the number of home structure fires reached an average of 1000 per day. Statistically, home fires killed an average of seven people in a day and could potentially cause roughly 28 USD in damage per second [5]. It was also estimated in the United States Fire Administration that the annual building fire deaths amounted up to 3050 from the years 2003 till 2012 [6]. According to the statistics by Australasian Fire and Emergency Service 
Authorities Council (AFAC), the residential deaths per 100,000 persons is between 0.1 and 0.7 during 19962004 [7]. They also reported most fire deaths (72\%) occurred between 8p.m. to 8a.m. in Australia and 78\% of fire deaths occurred between midnight to 4a.m. in New Zealand [8]. A study conducted by Xiong et al. highlighted that an alarming $80.5 \%$ of fire victims were asleep at the time of the ignition that subsequently led to their unfortunate demise [9].

Conventional safety system usually employed a fire or gas detector and alarm device. Smoke or fire detectors have many types with different specification and function depending on circumstances and demands. These detectors can be categorized as heat or thermal detectors, smoke or gas detectors, semiconductor gas detectors, and flame detectors [10]. From mid 1800s, heat or thermal type detectors had already been invented as the first autonomous fire detector [11]. This type of detectors has a fixed temperature that when exceeds will trigger the alarm. On the 1970's and 1980's, smoke or gas detectors considered to be a newer and popular invention [12]. These type of detectors usually detect fire in early flaming or smoldering stages. These detectors can be of different types having different operation principles, namely optical or photoelectric detectors, ionization detectors, air sampling detectors and others [13]. Photoelectric detectors works depending on the changes in the infrared beam dimming rate, which caused by smoke infiltration through the radiation path [14]. Semiconductor gas detector works by the principle of chemical reaction taking place between gas from fire incident and semiconductor material present inside the sensor [15]. Flame detectors suitable for fire and explosion detection with the ability to detect within three to four milliseconds from the UV radiation or infrared emitted from the fire. They are able to function well in highly sensitive environments, for instance aircraft maintenance facilities, fuel loading platforms, mines, refineries and high-tech industries [16].

Disadvantages of conventional safety system is that usually this kind of safety system only have one type of sensors. Generally, a fire detection system most often had only a single detector and to be used for a particular type of fire [17]. Every type of sensors has its own disadvantages, for example, heat or thermal type sensors are slow to be triggered and possible harm could have already took place when they reach the predefined detection point. Increase in distance between the sensor and the fire results in the responsiveness of the flame detector become progressively weaker [18]. Fire detectors solely based on chemical sensor technology can provide quicker response, however in the appearance of minor inconvenience they were still likely to trigger a false alarm [19] and typical smoke detectors could only sense smoke only after the fire had already reached toward a rigorous burning phase [20]. The likelihood of a false alarm being present is many times greater than the likelihood of a genuine fire [21]. Besides that, conventional safety system can only alert user within its vicinity. If the user is outside or not within its vicinity, traditional detectors cannot alert them. Conventional safety system also lacks in detecting power failure which could lead to massive losses. Conventional safety system has many disadvantages, hence a system to provide a comprehensive monitoring is needed which is why this paper propose the smart comprehensive safety monitoring system. The proposed system consists of five major components which is Arduino UNO, GSM SIM800, DHT11 as a temperature sensor, MQ-135 as a gas sensor and relay as a power failure sensor. Safety system which use fire and gas detector together simultaneously will result in better detection [22]. This safety system introduced sensors with GSM module so that the sensors can alert the user no matter where they are. This system can alert the user without geographical constraints and as a result, improves the safety system in the house or factory. By using MQ-135 gas sensors, this system able to detect harmful and poisonous gases such as ammonia (NH3), nitrogen oxides (NOx), benzene ( 6 6 6$)$, carbon dioxide $(\mathrm{CO} 2)$ and others that are dangerous in high concentration and have bad effects on human's health. The ability to detect power failure, which usually lacks in traditional safety systems will alert the user of the situation and as a result, the user can take appropriate actions to prevent damages or loss. SMS based smoke detector system gives warning immediately to multiple mobile numbers and hence remedy actions can be taken quickly.

\section{RESEARCH METHOD}

Figure 1 shows the block diagram for the Smart Safety Monitoring System. The hardware design entails of two main connections which are the connections between Arduino UNO with the temperature sensor (DHT11), the gas sensor (MQ-135) and the power failure sensor (relay) and the connections between Arduino UNO and the GSM SIM800. Arduino contain microprocessor that is used to develop command by using software on the computer [23]. The GSM module is used to communicate with the user's mobile number [24]. When a fire has broken out in the house or factory, DHT11 will trigger and send signal to the Arduino informing the high temperature, if there's a presence of harmful gases in the atmosphere, MQ-135 will trigger and send signal to the Arduino informing the presence of harmful gases and if power failure were to occur, relay will send signal to the Arduino informing the situation. The increased temperature or presence of harmful gases in the atmosphere and occurrence of power failure will make the Arduino to alert the user 
about the situation through GSM module. An SMS will be sent promptly to the user's smart phone or mobile phone to let the user know the increased in temperature, harmful gases or power failure in the house or factory.

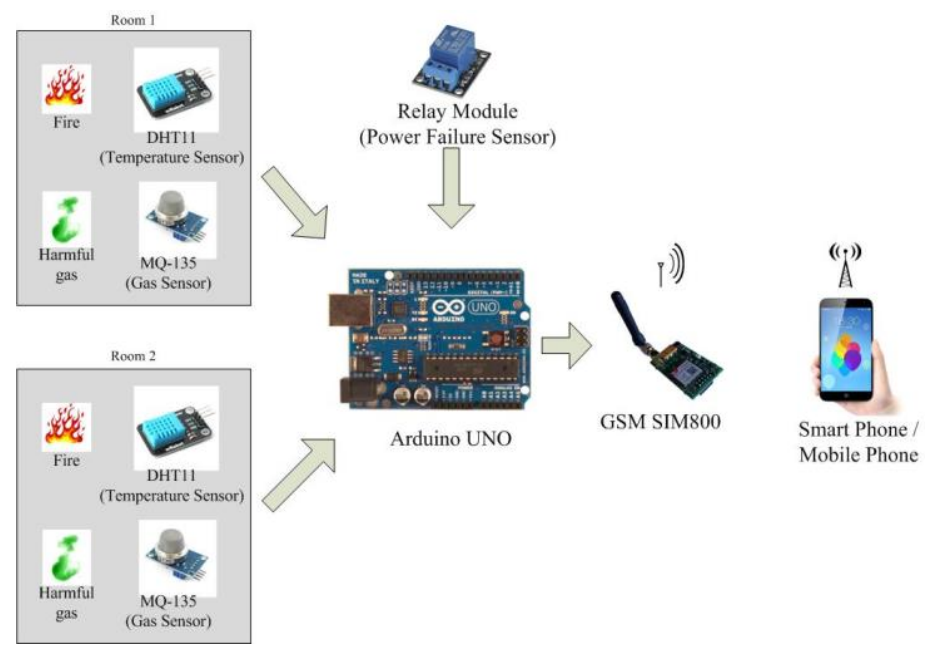

Figure 1. Block diagram of advanced gas leakage, fire and power supply failure monitoring system

Figure 2 shows the flow chart of the proposed system. When the system begins, DHT11 will always sense the surrounding temperature, MQ-135 will detects the presence of harmful gas in the surrounding atmosphere, while the relay will detect the power flow in case of power failure were to occur. Value of temperature limit that can be triggered by DHT11 can be changed in the code upon request by the user while the sensitivity of MQ-135 can be changed using the potentiometer. Whenever there's a rise in temperature, presence of harmful gases or occurrence of power failure, Arduino UNO will notify GSM module to send an alert message to the user's registered number. GSM module will send message to the user 3 times with an interval of 10 seconds in between.

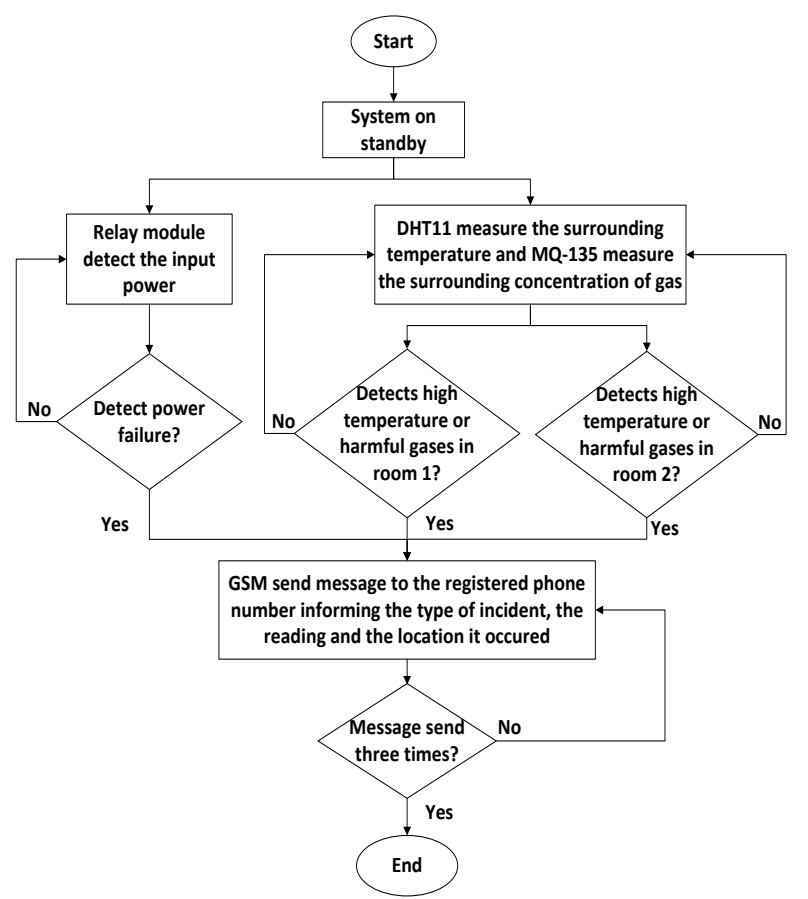

Figure 2. The flow chart of advanced gas leakage, fire and power supply failure monitoring system 


\section{RESULTS AND DISCUSSION}

The test was conducted by placing DHT11 and MQ-135 in two separate rooms while the relay was placed on the Arduino Uno power source. When there's a presence of high temperature, harmful gases or power failure, Arduino Uno will send signal to the GSM module to notify the user via SMS three times with an interval of 10 seconds in between informing the situation and location of the incident. Knowing the specific scene where a fire incident takes place would be extremely valuable to the user and authorities [25]. After 30 minutes, the system will return on standby mode. Tables 1 and 2 show the output results of the proposed system.

Table 1. The Result of the Output Temperature on DHT11, Surrounding Gas on MQ-135 and Power Failure on Relay

\begin{tabular}{|c|c|c|}
\hline \multirow{2}{*}{ Type of Sensors } & \multicolumn{2}{|r|}{ Data Collected } \\
\hline & Reading & Action \\
\hline DHT11 (Temnerature Sensor) & $<40^{\circ} \mathrm{C}$ & On standby \\
\hline DН1 11 (1 emperature sensor) & $\geq 40^{\circ} \mathrm{C}$ & GSM module send message to user \\
\hline MQ-135 (Gas Sensor) & $\begin{array}{l}<500 \text { PPM } \\
\geq 500 \text { PPM }\end{array}$ & $\begin{array}{c}\text { On standby } \\
\text { GSM module send message to user }\end{array}$ \\
\hline Relay (Power failure sensor) & $\begin{array}{c}\text { Detects power } \\
\text { Absence of power }\end{array}$ & $\begin{array}{c}\text { On standby } \\
\text { GSM module send message to user }\end{array}$ \\
\hline
\end{tabular}

Table 2. The Analysis on the GSM Output Performance

\begin{tabular}{ccc}
\hline Signal Strength (RSSI) & Result & Time taken for the message to reach user (s) \\
\hline $0(-115 \mathrm{dBm})$ & Failed to send message & - \\
$3(-108 \mathrm{dBm})$ & Failed to send message & - \\
$5(-104 \mathrm{dBm})$ & Successful in sending message & $5-10$ \\
$6(-102 \mathrm{dBm})$ & Successful in sending message & $5-7$ \\
$7(-100 \mathrm{dBm})$ & Successful in sending message & $4-5$ \\
$10(-94 \mathrm{dBm})$ & Successful in sending message & \\
\hline
\end{tabular}
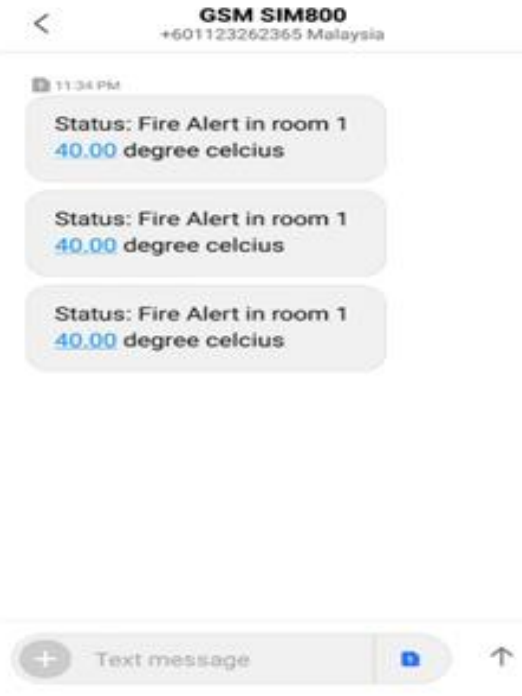

Figure 3. SMS received by the user to notify the fire existence

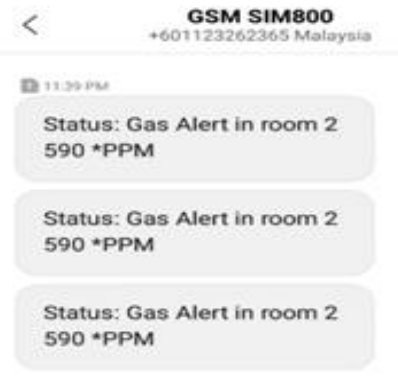

Figure 4. SMS received by the user to notify the presence of harmful gases

When DHT11 measure the surrounding temperature to be less than $40^{\circ} \mathrm{C}$, the system maintained on standby mode and DHT11 keep on measuring the surrounding temperature. Once DHT11 measure the surrounding temperature to be more than or equal to $40^{\circ} \mathrm{C}$, Arduino Uno will send signal to the GSM module to alert the user via SMS three times with 10 seconds of interval as shown in Figure 3 . The system returns to standby mode after 30 minutes passed. $40^{\circ} \mathrm{C}$ was set as the triggering temperature as it was an appropriate temperature to warn the user of the high temperature and at the same time provide enough time for the user to take action before the fire spread to a larger area. 
When MQ-135 measure the surrounding gas in the atmosphere to be less than 500 PPM, the system maintained on standby mode and MQ-135 keep on measuring the surrounding gas in the atmosphere. Once MQ-135 measure the surrounding gas to be more than or equal to 500 PPM, Arduino Uno will send signal to the GSM module to alert the user via SMS three times with 10 seconds of interval as shown in Figure 4 . The system returns to standby mode after 30 minutes passed. 500 PPM was set as the triggering value as it can be considered as in the early stage of danger level for gas in the atmosphere and provide enough time for the user to take action before the gas in the atmosphere becomes poisonous and causes severe harm.

When the relay detects power on the Arduino UNO power source, the system remains on standby. When the relay detects the absence of power, the system will be powered up by battery instead and Arduino UNO will send signal to the GSM module to alert the user via SMS three times with 10 seconds of interval as shown in Figure 5. The system then proceed as usual. The purpose of this sensor is not only to notify the user of the absence of power, but also to prevent losses such as disruption in security systems, pumps for aquariums and functioning of refrigerators which could bring losses to the homeowner while power failure in factories could lead to disruption in the factory's operation that could lead to massive losses.

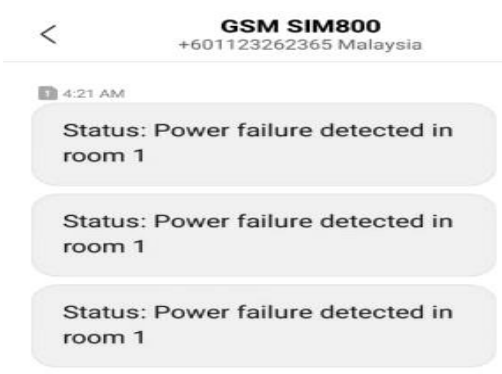

Figure 5. SMS received by the user to notify the power failure

\section{CONCLUSION}

The proposed project is an important comprehensive safety system which should be installed in houses or factories. Compared to traditional sensors, this system does not only monitor houses or factories from burning or fire accidents, but also monitors the air quality in the atmosphere thus creating a healthier surrounding of the house or factory. Besides that, this system also has a feature to detect power failure, which will alert the user promptly and as a result, the user can take appropriate actions to prevent damages or loss. Alerts from traditional sensors are limited to its own vicinity, but unlike the traditional sensors, this system features an alert system based on GSM network that can alert the user with no geographical constraints. This will allow the owner to take proper action and inform the authorities of the situation even if they are away from the house or factory. Future research should further develop this safety system by implementing an alarm system that will alert the surrounding or sprinkler system in case of a fire accident to occur and create a monitoring system that can display real time data at anytime and anywhere.

\section{ACKNOWLEDGEMENTS}

Authors gratefully acknowledge the financial support from Ministries of Higher Education Malaysia and Institute of Research Management and Innovation (IRMI) Universiti Teknologi MARA Grant No: 600IRMI/PERDANA 5/3 BESTARI (067/2018).

\section{REFERENCES}

[1] S. Farhana et al., "Intelligent, Low Cost, Real Time Flame Alarm System," 2018 IEEE 5th International Conference on Smart Instrumentation, Measurement and Application (ICSIMA), Songkla, Thailand, 2018, pp. 1-3. 
[2] J. L. Mikhanoshina and E. V. Sypin, "Flame detector as a basis of combined fire detector," 2014 15th International Conference of Young Specialists on Micro/Nanotechnologies and Electron Devices (EDM), Novosibirsk, 2014, pp. 283-285.

[3] P. Ghosh and P. K. Dhar, "GSM Based Low-cost Gas Leakage, Explosion and Fire Alert System with Advanced Security," 2019 International Conference on Electrical, Computer and Communication Engineering (ECCE), Cox'sBazar, Bangladesh, 2019, pp. 1-5.

[4] S. Abaya, E. Cabico, J. Domingo, R. Diaz, H. Kojima and R. Rivera, "An embedded system of dedicated and realtime fire detector and locator technology as an interactive response mechanism in fire occurrences," 2016 IEEE International Conference on Advances in Electronics, Communication and Computer Technology (ICAECCT), Pune, 2016, pp. 407-411.

[5] M. Ahrens, Home Structure Fires, National Fire Protection Association, 2013.

[6] U.S. Fire Administration, Residential Building Fires, 2014.

[7] Australasian Fire and Emergency Service Authorities Council, Accidental Fire Injuries in Residential Structures: Who's at Risk?, 2009

[8] Australasian Fire Authorities Council, Accidential Fire Fatalities in Residential Structures: Who's at Risk?, 2005.

[9] L. Xiong, M. Ball, D. Bruck, Comparative Investigation of 'Survival' and Fatality Factors in Accidental Residential Fires, Victoria University, 2013.

[10] N. Mahzan, N. Enzai, N. Zin and K. Noh, "Design of an Arduino-based home fire alarm system with GSM module", Journal of Physics: Conference Series, vol. 1019, p. 012079, 2018.

[11] Hussam Elbehiery, "Developed Intelligent Fire alarm system”, Journal of American Science. 8. 1016, 2012.

[12] O. Asif, M. Hossain, M. Hasan, M. Rahman and M. Chowdhury, "Fire-Detectors Review and Design of an Automated, Quick Responsive Fire-Alarm System Based on SMS", International Journal of Communications, Network and System Sciences, vol. 07, no. 09, pp. 386-395, 2014.

[13] A. Cote and P. Bugbee, Ionization Smoke Detectors. Principles of Fire Protection. National Fire Protection Association, 1988.

[14] C. Zhong, R. Wang and H. Ding, "Smoke-based video fire detectors sensitivity tests using smouldering cotton fire," 2016 3rd International Conference on Systems and Informatics (ICSAI), Shanghai, 2016, pp. 992-996.

[15] Li Jinghong, Zou Xiaohui and Wang Lu, "The design and implementation of fire smoke detection system based on FPGA," 2012 24th Chinese Control and Decision Conference (CCDC), Taiyuan, 2012, pp. 3919-3922.

[16] H. Mori, M. Ito and K. Sezaki, "Configuration-free propagation system for early fire alerts," 2016 IEEE International Conference on Pervasive Computing and Communication Workshops (PerCom Workshops), Sydney, NSW, 2016, pp. 1-6.

[17] GuoPing Jiang, Feng Shang, Fang Wang, XiJie Liu and TianShuang Qiu, "A Combined Intelligent Fire Detector with BP Networks," 2006 6th World Congress on Intelligent Control and Automation, Dalian, 2006, pp. 5417-5419.

[18] R. I. Rashid, S. M. Rafid and A. Azad, "An Automated Fire Suppression Mechanism Controlled using an Arduino," 2018 IEEE Distributed Computing, VLSI, Electrical Circuits and Robotics (DISCOVER), Mangalore (Mangaluru), India, 2018, pp. 49-54.

[19] A. Solórzano, J. Fonollosa, L. Fernández, J. Eichmann and S. Marco, "Fire detection using a gas sensor array with sensor fusion algorithms," 2017 ISOCS/IEEE International Symposium on Olfaction and Electronic Nose (ISOEN), Montreal, QC, 2017, pp. 1-3.

[20] J. L. Mikhanoshina and E. V. Sypin, "Flame detector as a basis of combined fire detector," 2014 15th International Conference of Young Specialists on Micro/Nanotechnologies and Electron Devices (EDM), Novosibirsk, 2014, pp. 283-285.

[21] T. Jandeweith, "The use of an expert system to expand a multi sensor fire detector to a robust fire detector," Proceedings The Institute of Electrical and Electronics Engineers. 29th Annual 1995 International Carnahan Conference on Security Technology, Sanderstead, Surrey, UK, 1995, pp. 214-218.

[22] O. Giandi and R. Sarno, "Prototype of fire symptom detection system," 2018 International Conference on Information and Communications Technology (ICOIACT), Yogyakarta, 2018, pp. 489-494.

[23] V. Neelapala and S. Malarvizhi, "Environment Monitoring System Based on Wireless Sensor Networks using Open Source Hardware," International Journal of Engineering Research and Sports Science, 2015.

[24] S. Gupta, N. Kumar and G. Tamizharasi, "Environment monitoring and device control using Arduino based embedded control sensor network," International Journal of Research, 2016, pp. 218-225.

[25] S. Majumder, S. O'Neil and R. Kennedy, "Smart apparatus for fire evacuation-An IoT based fire emergency monitoring and evacuation system," 2017 IEEE MIT Undergraduate Research Technology Conference (URTC), Cambridge, MA, 2017, pp. 1-4. 